\title{
Ethics and Genetically Modified Foods
}

\section{Gary Comstock}

lowa State U niversity

Ames, IA

Much of the food consumed in the United States is genetically modified (GM), i.e. derived from microorganisms, plants, or animals that have been manipulated at the molecular level to provide them with traits that farmers or consumers desire. These foods often are produced using techniques in which "foreign" genes are inserted into the microorganisms, plants, or animals. Foreign genes are those taken from sources other than the organism's natural parents. In other words, GM plants contain genes they would not have contained if researchers had only used traditional plant breeding methods.

Some consumer advocates object to GM foods on ethical grounds, and in such cases they typically have reasons for their opposition. In scrutinizing their reasons, we are practicing applied ethics. Applied ethics involves identifying peoples' arguments for various conclusions, and then analyzing those arguments to determine whether they support the conclusions. A critical goal here is to decide whether an argument is sound. A sound argument is one in which all of the premises are true and no mistakes have been made in reasoning.

Ethically justifiable conclusions inevitably rest on two kinds of claims: (a) empirical claims, or factual assertions about how the world is-claims ideally based on the best available scientific observations, principles, and theories, and (b) normative claims, or value-laden assertions about how the world ought to be-claims ideally based on the best available moral judgments, principles, and theories.

Is it ethically justifiable to produce genetically modified crops and foods? There is an objective answer to this question, and we will try here to figure out what it is. But we must begin with a proper, heavy, dose of epistemic humility, acknowledging that few ethicists at the moment seem to think that they know the final answer. 
Should the law allow GM foods to be grown and marketed? The answer to this, and every, public-policy question rests ultimately with us, citizens who will, in the voting booth and shopping market, decide the answer. To make up our minds, we will use feelings, intuitions, conscience, and reason. However, as we citizens are, by and large, not scientists, we must, to one degree or other, rest our factual understanding of the matter on the opinions of scientific experts. Therefore, ethical responsibility in the decision devolves heavily upon scientists engaged in the new GM technology.

\section{ETHICAL RESPONSIBILITIES OF SCIENTISTS}

Science is a communal process devoted to the discovery of knowledge, and to open and honest communication of knowledge. Its success, therefore, rests on two different kinds of values.

Epistemological values are those by which scientists determine which knowledge-claims are better than others. The values include clarity, objectivity, capacity to explain a range of observations, and ability to generate accurate predictions. Claims that are internally inconsistent are jettisoned in favor of claims that are consistent and in accord with established theories. (At times, anomalous claims turn out to be justifiable, and an established theory is overthrown, but these occasions are rare in the history of science.) Epistemological values in science also include: fecundity, the ability to generate useful new hypotheses; simplicity, the ability to explain observations with the fewest additional assumptions or qualifications; and elegance.

Personal values, including honesty and responsibility, are a second class of values that allows scientists to trust their peers' knowledge-claims. If scientists are dishonest, untruthful, fraudulent, or excessively self-interested, the free flow of accurate information so essential to science will be thwarted. If a scientist plagiarizes the work of others or uses fabricated data, that scientist's work will become shrouded in suspicion and otherwise reliable data will not be trusted. If scientists exploit those who work under them, or discriminate on the basis of gender, race, class, or age, then the mechanisms of trust and collegiality under-girding science will be eroded.

The very institution of scientific discovery is supported-indeed, permeated-with values. Scientists have a variety of goals and functions in society, so it should be no surprise that they face different challenges.

University and government scientists must be scrupulous in giving credit for their research to all who deserve it, careful not to divulge proprietary information, and painstaking in maintaining objectivity, especially when funded by industry. Industry scientists must also maintain the highest standards of scientific objectivity-a particular challenge since their work may not be subject to peer-review procedures as strict as those faced by university scientists. Industry scientists must also be willing to defend results of their 
research that are not favorable to their employer's interests. Scientists employed by nongovernmental activist organizations face challenges, as well. Their objectivity must be maintained in the face of an organization's explicit advocacy agenda, and in spite of the fact that their research might provide results that seriously undermine the organization's fund-raising attempts. All scientists face the challenges of communicating complex issues to a public that receives them through media channels that often are not equipped to communicate the qualifications and uncertainties attached to much scientific information.

At its core, science is an expression of some of our most cherished values. The public largely trusts scientists, and scientists must in turn act as good stewards of this trust.

\section{A Method for Addressing Ethical Issues}

Ethical objections to GM typically center on the possibility of harm to persons or other living things. Harm may or may not be justified by outweighing benefits. Whether harms are justified is a question that ethicists try to answer by working methodically through a series of questions ${ }^{1}$ :

1. What harm is envisaged? To provide an adequate answer to this question, we must pay attention to how significant the harm or potential harm may be (severe or trivial?); who the "stakeholders" are (who are the persons, animals, even ecosystems, that may be harmed?); the extent to which various stakeholders might be harmed; and the distribution of harms. The last question directs attention to a critical issue, the issue of justice and fairness: are those who are at risk of being harmed by the action in question different from those who may benefit from it?

2. What information do we have? Sound ethical judgments go hand-inhand with thorough understanding of the scientific facts. In a given case, we may need to ask two questions. Is the scientific information about harm being presented reliably? Is it fact, hearsay, or opinion? And, what missing information should we have before making the decision?

3. What are the options? In assessing the various courses of action, emphasize creative problem solving, seeking to find "win-win" alternatives in which everyone's interests are protected. Here we must identify each stakeholder's objectives; how many methods are available to achieve those objectives; and what advantages and disadvantages attach to each?

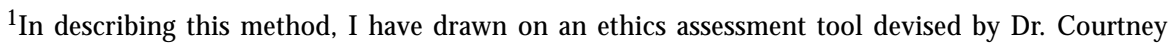
Campbell, Philosophy Department, Oregon State University, and presented at the Oregon State University Bioethics Institute in Corvallis, OR, Summer 1998.
} 
4. What ethical principles should guide us? There are at least three secular ethical traditions:

- Rights theory holds that we ought always to act so that we treat human beings as autonomous individuals, and not as mere means to an end.

- Utilitarian theory holds that we ought al ways to act so that we maximize good consequences and minimize harmful consequences.

- Virtue theory holds that we ought al ways act as would a just, fair, good person.

Ethical theorists are divided about which of these three is best. We manage this uncertainty through the following procedure. Pick one of the three principles. Using it as a basis, determine its implications for the decision at hand. Then, adopt a second principle. Determine what it implies for the decision at hand. Repeat the procedure with the third principle. Should all three principles converge on the same conclusion, then we have good reasons for thinking our conclusion morally justifiable.

How do we achieve moral closure? Does the decision we have reached allow all stakeholders either to participate in the decision or to have their views represented? If a compromise solution is deemed necessary in order to manage otherwise intractable differences, has the compromise been reached in way that has allowed all interested parties to have their interests articulated, understood, and considered? If so, then the decision may be justifiable on ethical grounds.

There is a difference between consensus and compromise. Consensus means that the vast majority of people agree about the right answer to a question. If the group cannot reach a consensus, but must, nevertheless, take some decision or other, then a compromise position may be necessary. But neither consensus nor compromise should be confused with the right answer to an ethical question. It is possible that a society might reach a consensus position that is unjust. For example, some societies have held that women should not be allowed to own property. That may be a consensus position, or even a compromise position, but it should not be confused with the truth of the matter. Moral closure is a sad fact of life; we sometimes must decide to undertake some course of action even though we know that, ethically, it may not be the right decision, all things considered.

\section{Ethical Issues Involved in the Use of Genetic TeChnology in Agriculture}

Discussions of the ethical dimensions of agricultural biotechnology are sometimes confused by a conflation of two quite different sorts of objections to GM technology: intrinsic and extrinsic. It is critical not only that we distinguish these two classes, but keep them distinct throughout the ensuing discussion of ethics. 
Extrinsic objections focus on the potential harms consequent upon the adoption of GMOs. Extrinsic objections hold that GM technology should not be pursued because of its anticipated results. Briefly stated, the extrinsic objections go as follows. GMOs may have disastrous effects on animals, ecosystems, and humans. Possible harms to humans include perpetuation of social inequities in modern agriculture, decreased food security for women and children on subsistence farms in developing countries, a growing gap between well capitalized economies in the northern hemisphere and less capitalized peasant economies in the south, risks to the food security of future generations, and the promotion of reductionistic and exploitative science. Potential harms to ecosystems include possible environmental catastrophe, inevitable narrowing of germplasm diversity, and irreversible loss or degradation of air, soils, and waters. Potential harms to animals include unjustified pain to those used in research and production.

These are valid concerns, and nation-states must have in place testing mechanisms and regulatory agencies to assess the likelihood, scope, and distribution of potential harms through a rigorous and well funded riskassessment procedure. For this reason, I contend that GM technology must be developed responsibly and with appropriate caution. However, these extrinsic objections cannot by themselves justify a moratorium, much less a permanent ban, on GM technology, because they admit the possibility that the harms may be minimal and outweighed by the benefits. How can one decide whether the potential harms outweigh potential benefits unless one conducts the research, field tests, and data analysis necessary to make a scientifically informed assessment?

In sum, extrinsic objections raise important questions about GMOs, and each country using GM Os ought to have in place the organizations and research structures necessary to ensure their safe use.

There is, however, an entirely different sort of objection to GM technology, which, if it is sound, would indeed justify a permanent ban.

Intrinsic objections allege that the process of making GMOs is objectionable in itself. This belief is defended in several ways, but almost all of the formulations are related to one central claim-the "unnatural ness objection" (UE): It is unnatural to genetically engineer plants, animals, and foods.

If UE is true, then we ought not to engage in bioengineering, however unfortunate may be the consequences of halting the technology. Were a nation to accept UE as the conclusion of a sound argument, then much agricultural research would have to be terminated and potentially significant benefits from the technology sacrificed. A great deal is at stake.

In Vexing Nature? On Ethical Case Against Agricultural Biotechnology, I discuss fourteen ways in which UE has been defended (Comstock, 2000). For present purposes, those fourteen objections can be summarized as follows: 
- To engage in ag biotech is to play God.

- To engage in ag biotech is to invent world-changing technology.

- To engage in ag biotech is illegitimately to cross species boundaries.

- To engage in ag biotech is to commodify life.

Let us consider each claim in turn.

To engage in ag biotech is to play God. In a western theological framework, humans are creatures, subjects of the Lord of the Universe, and it would be impious for them to arrogate to themselves roles and powers appropriate only for the Creator. Shifting genes around between individuals and species is taking on a task not appropriate for us, subordinate beings. Therefore, to engage in bioengineering is to play God.

There are several problems with this argument. First, there are different interpretations of God. Absent the guidance of any specific religious tradition, it is logically possible that God is a Being who wants to turn over to us all divine prerogatives; or explicitly wants to turn over to us at least the prerogative of engineering plants; or who does not care what we do. If God is any of these beings, then the argument fails because playing God in this instance is not a bad thing.

The argument seems to assume, however, that God is not like any of the gods just described. Assume that the orthodox Jewish and Christian view is correct, that God is the only personal, perfect, necessarily existing, all-loving, allknowing, and all-powerful being. In this traditional western theistic view, finite humans should not aspire to infinite knowledge and power. To the extent that bioengineering is an attempt to control nature itself, the argument is that bioengineering is an unacceptable attempt to usurp God's dominion.

The problem with this argument is that not all traditional Jews and Christians think that this God would rule out genetic engineering. I am a practicing evangelical Christian and the chairperson of my local Church Council. In my tradition, God is thought to endorse creativity, scientific and technological development, including genetic improvement. Other traditions have similar views. In the mystical writings of the Jewish Kabbalah, God is understood as One who expects humans to be co-creators, technicians working with God to improve the world. At least one Jewish philosopher, Baruch Brody (personal communication), has suggested that biotechnology may be a vehicle ordained by God for the perfection of nature.

Personally, I hesitate to think that humans can "perfect" nature. However, I have become convinced that GM might help humans to rectify some of the damage we have al ready done to nature. And I believe God may endorse such an aim. For humans are made in the divine image. God desires that we exercise the spark of divinity within us. Inquisitiveness in science is part of our nature. Creative impulses are not found only in the literary, musical, and plastic arts. 


\section{I hesitate to think that humans can "perfect" nature. However, I have become convinced that GM might help humans to rectify some of the damage we have already done to nature. And I believe $G$ od may endorse such an aim.}

They are part of molecular biology, cellular theory, ecology, and evolutionary genetics, too. It is unclear why the desire to investigate and manipulate the chemical bases of life should not be considered as much a manifestation of our god-like nature as the writing of poetry and the composition of sonatas. As a way of providing theological content for UE, then, this argument is unsatisfactory because it is ambiguous and contentious.

To engage in ag biotech is to invent world-changing technology, an activity that should be reserved to God alone. Let us consider this in conjunction with a similar objection: to engage in ag biotech is to arrogate historically unprecedented power to ourselves. The latter argument here is not the strong one, that biotech gives us divine power, but the more modest one, that it gives us a power we have not had previously. Also it would be counterintuitive to judge an action wrong simply because it has never been performed. In this view, it would have been wrong to prescribe a new herbal remedy for menstrual cramps, or to administer a new anesthetic. But that seems absurd. More argumentation is needed to call historically unprecedented actions morally wrong. What is needed is to know to what extent our new powers will transform society, whether we have witnessed prior transformations of this sort, and whether those transitions are morally acceptable.

We do not know how extensive the ag biotech revolution will be, but let us assume that it will be as dramatic as its greatest proponents assert. Have we ever witnessed comparable transitions? The change from hunting and gathering to agriculture was an astonishing transformation. With agriculture came not only an increase in the number of humans on the globe, but the first appearance of complex cultural activities: writing, philosophy, government, music, the arts, and architecture. What sort of power did people arrogate to themselves when they moved from hunting and gathering to agriculture? The power of civilization itself (McN eill, 1989).

Ag biotech is often oversold by its proponents. But suppose that they are right, that it will bring us historically unprecedented powers. Is this a reason to oppose it? Not if we accept agriculture and its accompanying advances, for when we accepted agriculture we arrogated to ourselves historically unprecedented powers.

In sum, these objections are not convincing. 
To engage in ag biotech is illegitimately to cross species boundaries. The problems with this argument are both theological and scientific. I will leave it to others to argue the scientific case that nature gives ample evidence of generally fluid boundaries between species. The argument assumes that species boundaries are distinct, rigid and unchanging, whereas, in fact, species now appear to be messy, plastic, and mutable. To proscribe the crossing of species borders on the grounds that it is unnatural seems scientifically indefensible.

It is also difficult to see how this objective could be defended on theological grounds. N one of the scriptural writings of the western religions proscribe genetic engineering, of course, because genetic engineering was undreamt of at the time the holy books were written. Now, one might argue that such a proscription may be derived from Jewish or Christian traditions of scriptural interpretation. Talmudic laws against mixing "kinds," for example, might be taken to ground a general prohibition against inserting genes from "unclean" species into clean species. Here is one way the argument might go: for an observant Jew to do what scripture proscribes is morally wrong; Jewish oral and written law proscribe the mixing of kinds (e.g., eating milk and meat from the same plate; yoking donkeys and oxen together); bioengineering is the mixing of kinds; therefore, for a Jew to engage in bioengineering is morally wrong.

But this argument fails to show that bioengineering is intrinsically objectionable in all of its forms for everyone. The argument might prohibit Jews from engaging in certain kinds of biotechnological activity but not all; it would not prohibit, for example, the transferring of genes within a species, nor, apparently, the transfer of genes from one clean species to another clean species. Incidentally, it is worth noting that the Orthodox community has accepted transgenesis in its food supply. Eighty to ninety percent of cheese produced in the United States is made using a GM product, chymosin. This cheese has been accepted as kosher by Orthodox rabbis (Gressel, 1998).

In conclusion, it is difficult to find a persuasive defense for this objection either on scientific or on religious grounds.

To engage in ag biotech is to commodify life. The argument here is that genetic engineering treats life in a reductionistic manner, reducing living organisms to little more than machines. Life is sacred and not to be treated as a good of commercial value only, to be bought and sold to the highest bidder.

Could we apply this principle uniformly? Would not objecting to the products of GM technology on these grounds also require that we object to the products of ordinary agriculture on the same grounds? Is not the very act of bartering or exchanging crops and animals for cash vivid testimony to the fact that every culture on earth has engaged in the commodification of life for centuries? If one accepts commercial trafficking in non-GM wheat and pigs, then why should we object to commercial trafficking in GM wheat and GM pigs? Why should it be wrong for us to treat DNA the way we have previously treated animals, plants, and viruses (N elkin and Lindee, 1995)? 
Although this objection may be true, it is not a sufficient reason to object to GM technology because our values and economic institutions have long accepted the commodification of life. Now, one might object that various religious traditions have never accepted commodification, and that genetic engineering presents us with an opportunity to resist, to reverse course. Leon Kass $(1988,1998)$, for example, has argued that we have gone too far down the road of dehumanizing ourselves and treating nature as a machine, and that we should pay attention to our emotional reactions against practices such as human cloning. Even if we cannot defend these feelings in rational terms, our revulsion at the very idea of cloning humans should carry great weight. Mary Midgley (2000) has argued that moving genes across species boundaries is not only "yukky" but, perhaps, a monstrous idea, a form of playing God.

Kass and Midgley have eloquently defended the relevance of our emotional reactions to genetic engineering but, as both admit, we cannot simply allow our emotions to carry the day. As Midgley writes, "Attention to ... sympathetic feelings [can stir] up reasoning that [alters] people's whole world view" (Midgely, 2000, p. 10). But as much hinges on the reasoning as on the emotions.

Are the intrinsic objections sound?Are they clear, consistent, and logical? Do they rely on principles we are willing to apply uniformly to other parts of our lives? Might they lead to counter-intuitive results?

We hesitate to accept counter-intuitive results because they run counter to widely-shared considered moral intuitions. If a moral rule or principle leads to counter-intuitive results, then we have a strong reason to reject it. For example, consider the following moral principle, which we might call the doctrine of naïve consequential ism (NC): al ways improve the welfare of the most people. Were we to adopt NC, then we would be not only permitted but required to sacrifice one healthy person if by doing so we could save many others. If six people need organ transplants (two need kidneys, one needs a liver, one needs a heart, and two need lungs) then NC instructs us to sacrifice the life of the healthy person so as to transplant their six organs to the other six. But this result, that we are obliged to sacrifice innocent people to save strangers, is wildly counter-intuitive. This result gives us a strong reason to reject $\mathrm{NC}$.

I have argued that the four formulations of the unnatural ness objection considered above are unsound insofar as they lead to counter-intuitive results. I do not take this position lightly. Twelve years ago, I wrote an article, The Case Against bGH (Comstock, 1988), which, I have been told, was one of the first papers by a philosopher to object to ag biotech on explicitly ethical grounds. I then wrote a series of other articles objecting to GM herbicide-resistant crops, transgenic animals, and, indeed, all of agricultural biotechnology (reprinted in Comstock, 2000). I am acquainted with worries about GM foods. But, for reasons that include the weakness of the intrinsic objections, I have come to change my mind. The sympathetic feelings on which my anti-GMO worldview was based did not survive the stirring up of reasoning. 


\section{Why Are We Careful With GM Foods?}

I do not pretend to know anything like the full answer to this question, but I would like to be permitted the luxury of brief speculation about it. The reason we are careful with GM foods may have to do with a natural, completely understandable, and wholly rational tendency to take precautions with what goes into our mouths. When we are in good health and happy with the foods available to us, we have little to gain from experimenting with a new food, and no reason to take a chance on a potentially unsafe food. We may think of this disposition as the precautionary response. When faced with two contrasting opinions about issues related to food safety, consumers place great emphasis on negative information. The precautionary response is particularly strong when a consumer sees little to gain from a new food technology. When a given food is plentiful, it is rational to place extra weight on negative information about any particular piece of that food.It is rational to do so, as my colleague Dermot Hayes has pointed out, even when the source of the negative information is known to be biased.

There are several reasons to take a precautionary approach to new foods. First, under conditions in which nutritious tasty food is plentiful, we have nothing to gain from trying a new food if, from our perspective, it is in other respects identical to our current foods. Suppose, on a rack in front of me, there are eighteen dozen maple-frosted Krispy Kreme doughnuts, all baked to a golden brown, all weighing three ounces. If I am invited to take one of them, I have no reason to favor one over the other. Suppose, however, that a naked man runs into the room with wild-hair flying behind him yelling that the sky is falling. He approaches the rack and points at the third doughnut from the left on the fourth shelf from the bottom and exclaims, "This doughnut will cause cancer! Avoid it at all costs, or die!" There is no reason to believe this man's claim and yet, since there are so many doughnuts freely available, why take a chance? It is rational to select other doughnuts, since all are alike. Now, perhaps one of us is a mountain climber who loves taking risks. They might be tempted to say, "Heck, I'll try that doughnut." In order to focus on the right question here, the risk-takers should ask themselves whether they would select the tainted doughnut to take home to feed to their two-year-old daughter. Why impose any risk on your loved ones when there is no reason to do so?

The Krispy Kreme example is meant to suggest that food tainting is both a powerful and an extraordinarily easy social act. It is powerful because it virtually determines consumer behavior. It is easy, because the tainter does not have to offer any evidence of the food's danger at all. Under conditions of plentiful food, rational consumers do and should take precautions, avoiding possibly tainted food no matter how untrustworthy the information source.

Our tendency to take precautions with our food suggests that a single person with a negative view of GM foods will be much more influential than many people with a positive view. The following experiment lends credibility to this 
hypothesis. In a willingness-to-pay experiment, Hayes and colleagues (in press) gave eighty-seven primary food shoppers $\$ 40$ each. Each participant was assigned to a group ranging in size from a half-dozen to a dozen members. Each group was then seated at a table at lunch-time and given one pork sandwich. In the middle of each table was one additional food item, an irradiated pork sandwich. Each group of participants was given one of three different treatments: (a) the Pro-irradiation treatment; (b) the Anti-irradiation treatment; or (c) the Balanced treatment.

Each treatment began with all of the participants at a table receiving the same, so-called "neutral" description of an irradiated pork sandwich. The description read, in part:

The U nited States F ood and Drug Administration has recently approved the use of ionizing radiation to control Trichinella in pork products.

This process results in a 10,000-fold reduction in Trichinella organisms in meat. The process does not induce measurable radioactivity in food.

After the participants read this description, they would proceed to conduct a silent bid in order to purchase the right to exchange their non-irradiated sandwich for the irradiated sandwich. Whoever bid the highest price would be able to buy the sandwich for the price bid by the second-highest bidder. In order to provide participants with information about the opinions of the others at their table so that they could factor this information into their future bids, the lowest and highest bids of each round were announced before the next round of bidding began. At the end of the experiment, one of the ten bidding rounds would be selected at random, and the person bidding the highest amount in that round would have to pay the second-highest price bid during that round for the sandwich.

After five rounds of bidding, the second-highest bids in all three groups settled rather quickly at an equilibrium point, roughly, twenty cents. That is, someone at every table was willing to pay twenty cents for the irradiated pork sandwich, but no one in any group would pay more than twenty cents. The bidding was repeated five times in order to give participants the opportunity to respond to information they were getting from others at the table, and to ensure the robustness of the price.

After five rounds of bidding, each group was given additional information. Group (a), the so-called Pro group, was provided with a description of the sandwich that read, in part:

Each year, 9,000 people die in the United States from food-borne illness. Some die from Trichinella in pork. Millions of others suffer short-term illness. Irradiated pork is a safe and reliable way to eliminate this pathogen. The process has been used successfully in twenty countries since 1950. 
The Pro-group participants were informed that the source of this positive description was a pro-irradiation food-industry group. After the description was read, five more rounds of bidding began. The price of the irradiated sandwich quickly shot upward, reaching sixty cents by the end of round ten. A ceiling price was not reached, however, as the bids in every round, including the last, were significantly higher than in the preceding round-the price was still going up when the experiment was stopped (Figure 1).

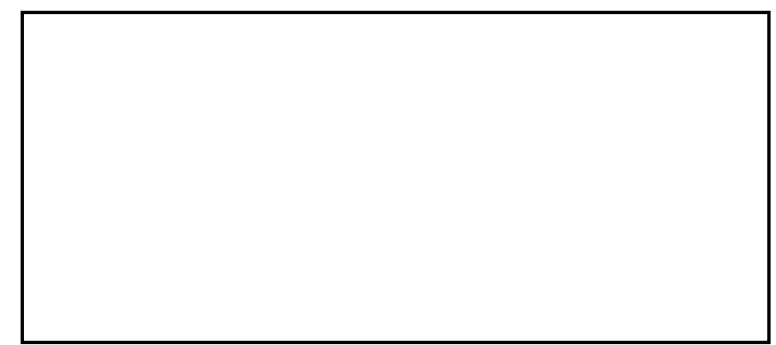

\section{Figure 1. Effect of information on average bid for irradiated pork [reprinted from Hayes et al. (in press)].}

After its first five rounds of bidding, Group (b), was provided with a different description. It read, in part:

In food irradiation, pork is exposed to radioactive materials. It receives 300,000 rads of radiation - the equivalent of thirty million chest $X$ rays. This process results in radiolytic products in food. Some radiolytic products are carcinogens, and linked to birth defects. The process was developed in the 1950s by the Atomic Energy Commission.

The source of this description was identified to the bidders as "Food and Water," an anti-irradiation activist group in England. After Group (b) read this description, it began five more rounds of bidding. The bid went down, quickly reaching zero. After the first five rounds produced a value of twenty cents in Group (b) for the pork sandwich described in a "neutral" way, no one in this group would pay a penny for the irradiated sandwich described in a "negative" way. This result obtained even though the description was clearly identified as coming from an activist, non-scientific group.

After five rounds of bidding on the neutral description, the third group, Group (c), received both the positive and negative descriptions. One might expect that this group's response would be highly variable, with some participants scared off by the negative description and others discounting it for its unscientific source. Some participants might be expected to bid nothing while others would continue to bid highly. However, the price of the sandwich in the third, so-called Balanced group, also fell quickly. Indeed, the price reached zero almost as quickly as it did in Group (b), the negative group. That is, even though the third group had both the neutral and the positive 
description in front of them, no one exposed to the negative description would pay two cents for the irradiated sandwich.

Hayes' study illuminates the precautionary response, and carries implications for the GM debate. These implications are that, given neutral or positive descriptions of GM foods, consumers initially will pay more for them. Given negative descriptions of GM foods, consumers initially will not pay more for them. Finally, and this is the surprising result, given both positive and negative descriptions of GM foods, consumers initially will not pay more for them. Both sides in the GM food debate should be scrupulous in providing reasons for all of their claims, especially negative claims.

In a worldwide context, the precautionary response of those facing food abundance in developed countries may lead us to be insensitive to the conditions of those in less fortunate situations. Indeed, we may find ourselves in the following ethical dilemma.

\section{In a worldwide context, the precautionary response of those facing food abundance in developed countries may lead us to be insensitive to the conditions of those in less fortunate situations.}

For purposes of argument, let us make the following three assumptions, none of which is implausible. First, assume that GM food is safe. Second, assume that some GM foods, such as rice enhanced with iron or vitamin A, virus-resistant cassava, or aluminum-tolerant sweet potato, may be of great potential benefit to millions of poor children. Third, assume that widespread anti-GM information and sentiment, no matter how unreliable on scientific grounds, could shut down the GM infrastructure in the developed world.

Under these assumptions, consider the possibility that by condemning GM foods in the countries best suited to conduct GM research safely, activists could bring to a halt the range of money-making GM foods marketed by multinational corporations. This result might be a good or a bad thing. However, an unintended side-effect would be that the new GM crops mentioned above might not be forthcoming, assuming that their development and commercialization depends upon the addressing of fundamental questions in plant science and molecular biology that will be answered only if research in private industry is allowed to progress along with that in public research institutions.

Our precautionary response to new food may put us in an uncomfortable position. On the one hand, we want to tell "both sides" of the GM story, letting people know both about the benefits and the risks of the technology. On the other hand, some of the people touting the benefits of the technology make outlandish claims that it will feed the world while some of the people decrying 
the technology make unsupported claims that it will ruin the world. In this situation, however, those with unsupported negative stories to tell carry greater weight than those with unsupported positive stories. Our precautionary response, then, may well lead, in the short term at least, to the rejection of GM technology. Yet, this rejection could indirectly harm those children most in need.

Are we being forced to choose between two fundamental values, the value of free speech versus the value of children's lives?

On the one hand, open conversation and transparent decision-making processes are critical to the foundations of a liberal democratic society. We must reach out to include everyone in the debate, and allow people to state their opinions about GM foods, whatever those opinions happen to be, whatever the level of acquaintance with the science and technology happens to be. Free speech is a value not to be compromised lightly.

On the other hand, simply stating negative opinions about GM food can clearly have a tainting effect, a powerful and extraordinarily easy consequence of free speech. Tainting the technology might result in the loss of this potentially useful tool. Should we, then, draw some boundaries around the conversation, insisting that each contributor bring some measure of scientific data to the table, especially when negative claims are being made? Or are we collectively prepared to leave the conversation wide open? That is, in the name of protecting free speech, are we prepared to risk losing an opportunity to help some of the world's most vulnerable?

\section{Religion and Ethics}

Religious traditions provide an answer to the question, "How, overall, should I live my life?" Secular ethical traditions provide an answer to the question, "What is the right thing to do?" When in a pluralistic society a particular religion's answers come into genuine conflict with the answers arrived at through secular ethical deliberation, we must ask how deep is the conflict. If the conflict is so deep that honoring the religion's views would entail dishonoring another religion's views, then we have a difficult decision to make. In such cases, the conclusions of secular ethical deliberation must over-ride the answers of the religion in question. The reason is that granting privileged status to one religion will inevitably discriminate against another religion. Individuals must be allowed to follow their conscience in matters theological. But if one religion is allowed to enforce its values on others in a way that restricts the others' ability to pursue their values, then individual religious freedom has not been protected.

M oral theorists refer to this feature of nonreligious ethical deliberation as the overridingness of ethics. If a parent refuses a lifesaving medical procedure for a minor child on religious grounds, the state is justified in overriding the parent's religious beliefs in order to protect what secular ethics regards as a value higher than religious freedom: the life of a child. 
The overridingness of ethics applies to our discussion only if a religious group claims the right to halt GM technology on purely religious grounds. The problem here is the confessional problem, of one group attempting to enforce its beliefs on others. I mean no disrespect to religion; as I have noted, I am a religious person, and I value religious traditions other than my own. Religious traditions have been the repositories and incubators of virtuous behavior. Yet each of our traditions must in a global society learn to coexist peacefully with competing religions, and with nonreligious traditions and institutions.

If someone objects to GM technology on purely religious grounds, we must ask on what authority they speak for their tradition, whether there are other, conflicting, views within their tradition, and whether acting on their views will entail disrespecting the views of people from other religions. It is, of course, the right of each tradition to decide its attitude about genetic engineering. But in the absence of other good reasons, we must not allow someone to ban GM technology for narrowly sectarian reasons alone. To allow such an action would be to disrespect the views of people who believe, on equally sincere religious grounds, that GM technology is not necessarily inconsistent with God's desires for us.

\section{MINORITY VIEWS}

When, in a pluralistic society, the views of a particular minority come into genuine conflict with the views of the majority, we must ask a number of questions. How deep is the conflict? How has the minority been treated in the past? If the minority has been exploited, have reparations been made? If the conflict is so deep that honoring the minority's views would entail overriding the majority's views, then we have a difficult decision to make. In such cases, the conclusions of the state must be just, taking into account the question of past exploitation and subsequent reparations, or lack thereof. This is a question of justice.

The question of justice would arise in the discussion of GM technology if the majority favored GM technology while the minority claimed the right to halt GM technology. If the minority cited religious arguments to halt GMOs, yet the majority believed that halting GMOs would result in loss of human life, then the state faces a decision very similar to the one discussed in the prior section. In this case, secular policy decisions may be justified in overriding the minority's religious arguments insofar as society deems that human life has a value higher than that of religious freedom.

However, should the minority cite past oppression as the reason that their values ought to predominate over the majority's, then a different question must be addressed. Here, the relevant issues have to do with the nature of past exploitation, its scope and depth, and the sufficiency of efforts- if there have there been any-to rectify the injustice and compensate victims. If the problem is long-standing and has not been addressed, then imposing the will of the majority would seem a sign of an unjust society insensitive to its past misdeeds. 
If, on the other hand, the problem has been carefully addressed by both sides and, for example, just treaties-arrived at through fair procedures and enforced-are rectifying past wrongs and are preventing new forms of exploitation, then the minority's arguments would seem to be far weaker. This conclusion would be especially compelling if it could be shown that the lives of other disadvantaged peoples might be put at risk by honoring a particular minority's wish to ban GMOs.

\section{CONCLUSION}

Earlier I described a method for reaching ethically sound judgments. On the basis of that method I personally came to change my mind about the moral acceptability of GM crops. My opinion changed as I took full account of three considerations: (a) the rights of people in various countries to choose to adopt GM technology (a consideration falling under the human rights principle); (b) the balance of likely benefits over harms to consumers and the environment from GM technology (a utilitarian consideration); and (c) the wisdom of encouraging discovery, innovation, and careful regulation of GM technology (a consideration related to virtue theory).

Is it ethically justifiable to pursue genetically modified crops and foods? I have come to believe that three of our most influential ethical traditions converge on a common answer. Assuming we proceed responsibly and with appropriate caution, the answer is yes.

\section{ACKNOWLEDGMENTS}

I learned much from discussing these ideas with several colleagues, including Gary Varner, Tony Smith, N ed Hettinger, M arc Saner, Rob Streiffer, Dermot Hayes, Kristen Hessler, Fred Kirschenmann, and C.S. Prakash. I was also fortunate to participate in several conversations on the topic during the past few months, and would like to express gratitude to my hosts, including:

- Three local chapters of the American Chemical Society at: Eastern Oregon University (Richard Hermens); Washington State University (Roger Willett); and Seattle University (Susan Jackels), in October 2000.

- The "New Zealand Royal Commission on Genetic Modification"; a public audience in Wellington, $\mathrm{N}$ ew Zealand (sponsored by the $\mathrm{N}$ ew Zealand Life Sciences Network, and Francis Wevers); and St. John's College, Auckland, NZ (Graham Redding), November 2000.

- The "Plant Sciences Institute Colloquium," I owa State University, February 2001 (Stephen Howell).

- "Biotech Issues 2001," an Extension In-Service conference at Colorado State University (Bob Zimdahl and Pat Kendall); and a seminar in the CSU Philosophy Department (Phil Cafaro and Holmes Rolston); both in February. 
- The 2001 Annual Meeting of the American Association for the Advancement of Science, San Francisco, in February (Katherine R. Smith and Nicole Ballenger).

- A seminar at the Center for International Development and Science, the Technology and Public Policy Program, and the Belfer Center for Science and International Affairs, Harvard University, March, 2001 (Calestous Juma and Derya Honca).

- The Center for Judaism and the Environment, and Center for Business Ethics, Jerusalem College for Technology, Israel (Akiva Wolff, Pinchas Rosenstein, and Jacqueline Rose); and "Symposium 2001: Plant Biotechnology, Its Benefits Versus Its Risks," Tel Aviv University, Israel, May 2001 (Bernie Epel and Roger Beachy).

"Ethical Issues Involved in the Use of Genetic Technology in Agriculture" is reprinted from pp. 182-195 of Comstock (2000), with the kind permission of the publisher.

Other portions of the paper were written with support of the Cooperative State Research, Education, and Extension Service, U.S. Department of Agriculture, under Agreement N 0. 00-52100-9617.

\section{References ANd Notes}

Comstock G (1988) The case against bGH. Agriculture Human Values 5 36-52. Comstock G (2000) Vexing Nature? On the Ethical Case against Agricultural Biotechnology. Boston/Dordrecht: Kluwer Academic Publishers.

Gressel J (1998) Observation at the annual meeting of the Weed Science Society of America Chicago 10 February.

Hayes D et al. (in press) Consumer preferences for food irradiation: how favorable and unfavorable descriptions affect preferences for irradiated pork in experimental auctions. Journal of Risk and Uncertainty.

Kass L (1988) Toward a M ore Natural Science: Biology and Human Affairs. N ew York: The Free Press.

Kass L (1998) Beyond biology: Will advances in genetic technology threaten to dehumanize us all? The New York Times on the Web, August 23, http:// www.nytimes.com/books/98/08/23/reviews/980823.23kassct.html.

McN eill W (1989) Gains and losses: an historical perspective on farming. The 1989 lowa Humanities Lecture (N ational Endowment for the Humanities and Iowa Humanities Board, Oakdale Campus, Iowa City, IA, 1989), p 5.

Midgley M (2000) Biotechnology and Monstrosity: Why We Should Pay Attention to the 'Yuk Factor.' Hastings Center Report 30 no. 5, 7-15. Nelkin D Lindee MS (1995) The DNA Mystique: The Gene as Cultural Icon. New York: Freeman. 
Q: I have a background as an ethicist, and I have yet to hear an ethical principle enunciated clearly, such that it has clear practical implications that are not subject to some clear counter example. Exactly how seriously should we take the claim that intrinsic objections are really supposed to provide an absolute bedrock for morality, as opposed to just one of the many values we have to take into account and balance with lots of other values?

A: As I understand it, your question is exploring a defense of the intrinsic objections along the following lines-look, no one bases their objections to GMOs just on the fact that they think it is playing God, or just on the fact that it is tinkering with nature. Rather, all of these go together to form a package, and the cumulative result of worrying about all of them is the basis of their view. Is that close enough?

Q: Something like that. But also, just from an epistemological or an ethical perspective, we don't know yet of any fundamental ethical theory that is not counter-intuitive. So, isn't your method going to basically prove that all ethical principles are wrong, if your method is correct? Take one of the principles that you enunciated at the end. Ensure that all stakeholders are heard-do you really want to endorse that as stated, that every single stakeholder has to be heard? We are going to be sitting around for thousands of years waiting for everybody to finish.

A: Yes, it's a good question. Let me answer the one that I articulated before, then I'Il try to respond to that one. It is appealing to me to think that the whole is greater than the sum of the parts, but I just don't think that is true. In this case, what we have to do, if we want to think responsibly about these objections, is to look at each one. And if each one turns out to be radically counter-intuitive then the whole is less than the sum of the parts. On the question of whether we have any principles that don't lead to counter-intuitive results, I am much more optimistic than you are about that. I agree that ethical theorists haven $t$ yet articulated such a theory, but, in terms of secular ethics, we haven't been at it very long- less than three or four decades by my reckoning - and I think we will get closer to it than you seem to think. And finally, notice that these really aren't ethical principles that lead to counterintuitive results, they are more like rules of thumb-how shall we act in this or that case- and there you are probably right, that we can find a counter example to any such rule of thumb. But I am less certain that real principles are subject to defeat so easily.

Q: I think it is fair to say that at least some critics do take their principles to be absolute, in the sense that they think that saying that suffices to show that these things are wrong. And so, if you do get a single counter example, then I think that does cause trouble for them. I think I agree with you on that point.

A: I am impressed, by the way, by how quickly critics run from these principles. That is, once they are enunciated - I have had this happen to me- 
someone al ways stands up and says, "That's not why we are opposed to GM Os!" And I say, "Okay, good. What are the reasons?" And then they typically turn to the ones that NABC addresses in depth-safety, environmental consequences, and so on-which is where the attention should be, in my view.

Q: As I understood your talk, you said that you have changed your view, from being more anti to pro genetically engineered crops. When you held your previous view, was it based in any way on these intrinsic objections, or was it solely based on extrinsic considerations of the risks and benefits?

A: I think I had the intrinsic objections in the back of my mind. But, in my writings, my objections were typically more consequentialist. I was concerned about the effects of the new technology on family farmers, primarily- extrinsic concerns about economic and social dislocating effects. I was concerned about animal welfare, and still am; that's an extrinsic concern. Does that address your question?

Q: Yes. I was curious if it was based on an intrinsic one, what changed your mind on that. It sounds like what changed your mind was a broader look at the technology and its potential benefits. I wanted to confirm that.

A: Yes, thank you.

Q: Your previous writings, when you were an opponent of biotechnology, have been used by people to back up their beliefs. N ow that you have changed your views, do you have to become more of an activist for the other side? Or do I have to read the book?

A: Reading the book is a good start! Given the consequences of negative information that I just showed you, I have a duty now to be as active for my current views as I used to be for my old views. Which is why I try to get out as much as I can, and talk.

Q: I appreciate the talk. But you leave nothing of nature standing. People want to distinguish between the natural and the unnatural, and one way they do it is to talk about species boundaries. And your entire argument against those who would not cross species boundaries is, "That would rule out mules." So be it. I'll accept that consequence. But the more important question: is there any way we can use the concept, or the idea of nature and the natural, in ethical or esthetic discourse, if we accept biotechnology as natural? And if we don't accept it as natural, then it would seem that the people who criticize it on the grounds that it is against nature may be right.

A: The questioner, Mark Sagoff, has done more than perhaps anyone in the world to think about what is natural and unnatural, so I hesitate to try to respond quickly. I do have arguments to offer other than if you accept mules you must accept GM Os, which I didn't have time to go through. But, in general, I am very skeptical about the natural/unnatural distinction. I don't think it will 
cut much ice in the end, once we try to sort out what is natural and what is unnatural. There are so many different places to cut the joints. In the end, there are better conceptual categories to use, such as sentient or non-sentient, living or non-living, humanly influenced or not humanly influenced, wild or domesticated, and those, I suspect, in the long run will get us further faster. And I learned that from Mark.

\section{FURTHER READING}

Comstock G (2000) Make plans on the hoof, Times Higher Education Supplement, December 22-29.

Comstock G (in press) Life Science Ethics. Ames: Iowa State University Press.

Reiss M Straughan R (1996) Improving Nature: The Science and Ethics of Genetic Engineering. Cambridge: Cambridge University Press.

Shrader-Frechette K (1991) Risk and Rationality: Philosophical Foundations for Populist Reforms. Berkeley: University of California Press.

Thompson P (1997) Food Biotechnology in Ethical Perspective. London: Blackie. 